\title{
Multiple osteochondroses and avulsion fracture of anterior superior iliac spine in a soccer player
}

\author{
M N Doral, S T Aydog, O Tetik, O A Atay, E Turhan, H A Demirel
}

Br J Sports Med 2005;39:e16 (http://www.bjsportmed.com/cgi/content/full/39/3/e16). doi: 10.1136/bjsm.2004.013979

Apophysitis describes a chronic traction injury at the insertion site of a tendon. There is a gradual onset of pain with no clear history of injury. Without adequate preventive methods, an avulsion fracture may result. The case is here reported of an apophyseal avulsion fracture of the anterior superior iliac spine in an adolescent caused by playing football before the end of treatment for apophysitis. An open reduction and internal fixation was performed followed by a rehabilitation programme. No complications occurred, and the patient had returned to his previous level of sporting activity after six weeks.

A pophysitis describes a chronic traction injury at the tendon insertion site, and includes gradual onset of pain with no clear history of injury, whereas an apophyseal avulsion fracture is usually acute, and the displaced fragment may be bony or cartilaginous. ${ }^{1}$ Apophyseal injuries occur in skeletally immature patients, primarily aged $12-17$, not only in the knee region, but also in the pelvis region in patients aged $14-25 .^{23}$ There are reports of multiple apophysitis in the literature. ${ }^{45}$

We here report the case of an avulsion fracture of the anterior superior iliac spine (ASIS) in a 16 year old amateur footballer, who had been followed up by us with the diagnosis of Osgood-Schlatter's disease for the preceding two years.

\section{CASE REPORT}

The patient first presented with pain on the anterior side of both knees when he was 14 years old. From clinical and radiological examinations, he was diagnosed as having grade I Osgood-Schlatter's disease (fig 1); conservative treatment was prescribed consisting of an exercise programme and activity restriction. ${ }^{6}$ During the follow up period, there were no serious problems except some times when his training load was too high.

After two years he was readmitted to our clinic with groin pain on his right side. There had been no major traumatic event. The pain worsened with exercise and disappeared with rest. On physical examination, there was pain at the right ASIS with palpation. During active flexion and external rotation of the hip, the pain increased. The diagnosis was apophysitis of the ASIS, and the patient was advised to reduce the frequency and intensity of training.

Instead of modifying his training sessions as advised, the patient kept playing football at the same level, and tried to play in a regular game. Two weeks after his diagnosis, he presented complaining of pain in the right hip and difficulty in walking. In the 2 nd minute of the football match, he had felt acute (sudden) pain in his right groin when kicking the ball with his right foot. He was not able to continue the match.
On physical examination, he had tenderness, crepitation, and swelling over the right ASIS, and was unable to straight raise his right leg because of the pain. There was no active flexion-extension or internal-external rotation.

Posteroanterior pelvis and posteroanterior and lateral hip radiographs of both sides were obtained. Unilateral avulsion of the ASIS was revealed (fig 2). The avulsed fragment was displaced $2.5 \mathrm{~cm}$. Blood tests showed no acute phase reactants or markers of inflammation such as anti(streptolysin O), C reactive protein, rheumatoid factor, or erythrocyte sedimentation rate. Open reduction and internal fixation was our treatment of choice. The surgical approach was started by a small anterior iliofemoral incision. After exploration of the avulsed fragment (fig 3), we manipulated it and debrided the area on the anterior part of the iliac bone. The preliminary reduction was achieved by towel clamp after debridement of the undersurface of the mostly osteochondral fragment. This was $2 \times 3 \mathrm{~cm}$ in size and very strongly attached to the hip flexor muscles. The fragment was reduced into its original place and internally fixed by two cortical screws with washers and one K wire (figs 4 and 5).

The fixation was stable and no motion was observed during the preoperative control of the passive range of motion of the hip.

The rehabilitation programme was as follows. On the first day after surgery, the patient was taught to mobilise on crutches. During the first week, he started exercises to improve hip mobility. Two weeks after the operation, he started to gradually decrease use of crutches. Four weeks after the operation, he was allowed to start easy training. Six weeks after the operation, he had returned to his normal training and competition routine (fig 6). Eight weeks after the operation, he started to play at the competitive level. There were no complications.

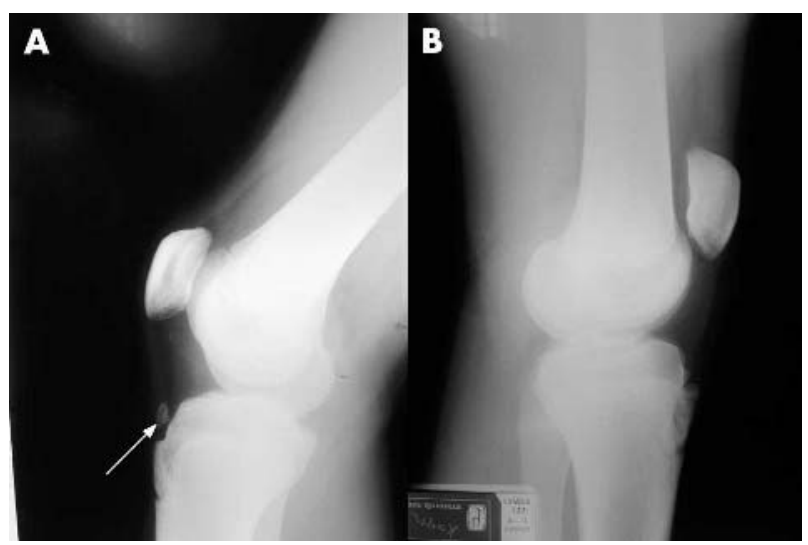

Figure 1 Lateral radiographs of $(A)$ the right knee and $(B)$ the left knee. 


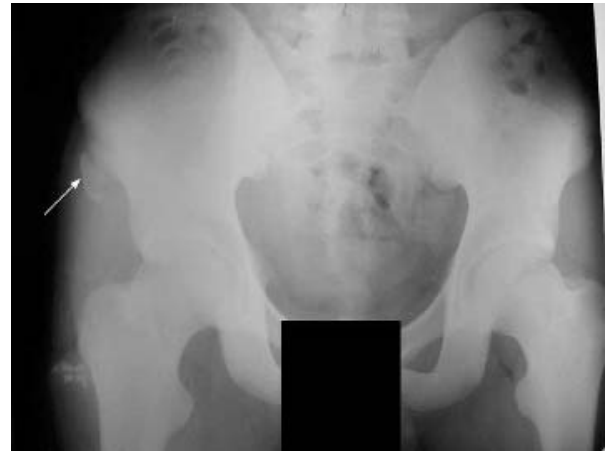

Figure 2 Preoperative radiograph showing avulsed fragment of the right anterior superior iliac spine.

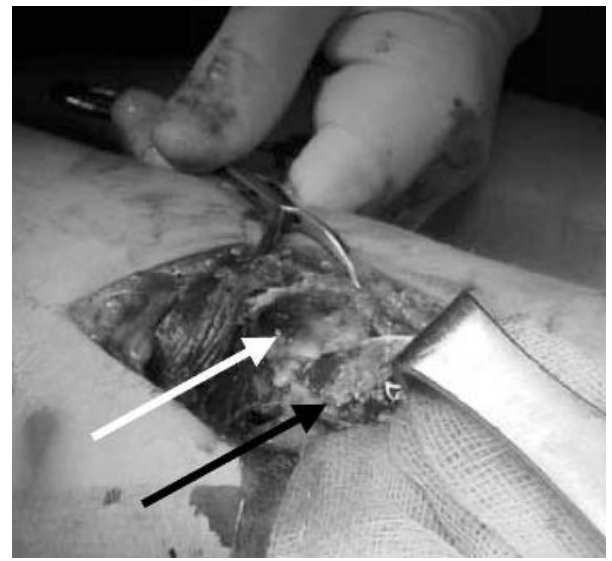

Figure 3 Exploration of the avulsed fragment. White arrow, avulsed fragment; black arrow, anterior superior iliac spine.

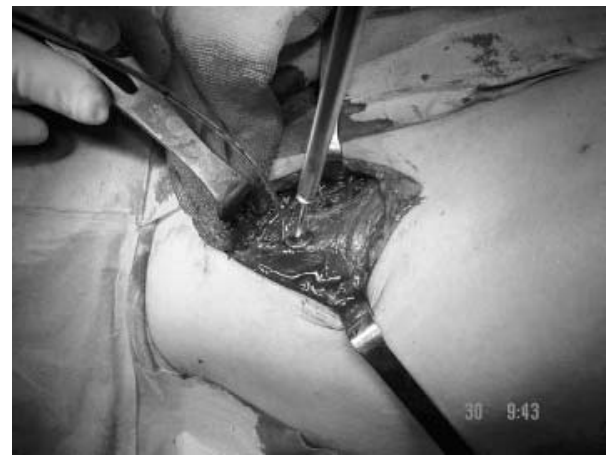

Figure 4 Fixation of the avulsed fragment.

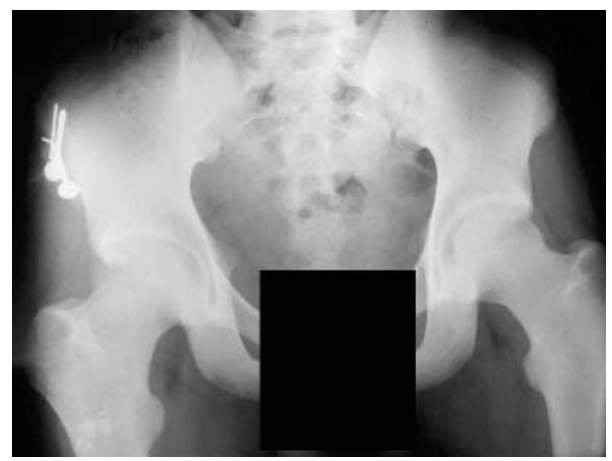

Figure 5 Postoperative radiograph showing internal fixation materials.

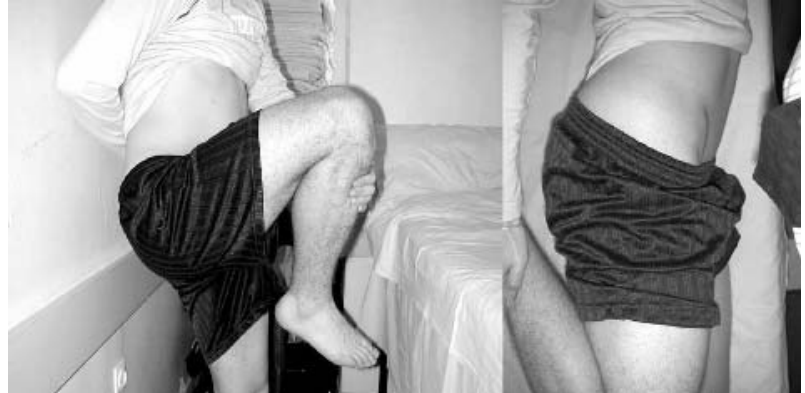

Figure 6 Normal range of movement six weeks after the operation. Permission for the publication of this figure was obtained from the patient.

\section{DISCUSSION}

In this case report, our patient had Osgood-Schlatter's disease in both knees and an avulsion fracture in the right ASIS. To the best of our knowledge, this is the first report of a combination of two cases of apophysitis on the same side.

Apophyses are specific regions of ossification where longitudinal growth takes place. Generally, strong muscles are inserted on to these structures. In young athletes, overuse injuries to these structures may result in apophysitis. ${ }^{7}$ Avulsion fractures of the apophyses usually occur as a result of a sudden contraction of muscle on immature bone. Injuries of the ASIS, the anterior inferior iliac spine, and the ischial tuberosity have been described in children and adolescent footballers, caused by a sprint or sudden flexion of the hip during the kicking phase. ${ }^{8-10}$ In our case, hyperextension of the hip and flexion of the knee resulted in the avulsion fracture of the ASIS with apophysitis during the kicking. This suggests that treatment of apophysitis should be undertaken more seriously than was thought to prevent serious situations such as avulsion fractures. ${ }^{11}$

Avulsion fractures around the pelvis are usually treated by conservative means, consisting of initial bed rest, non-weight bearing, and gradual mobilisation. Most previous reports of injuries located at the iliac crest, ASIS, and anterior inferior iliac spine have shown good or excellent recovery. ${ }^{812}{ }^{13}$ When displacement of the avulsed apophysis is more than $2 \mathrm{~cm}$, a surgical procedure is recommended. ${ }^{74}$ Therefore, we performed open reduction and internal fixation in our case. There are reports of track athletes who achieved return to sport four weeks after surgery. As our patient was involved in a contact sport, we only allowed him to return to sporting activity at the 6th week and to play football at the 8th week. At the 6th month follow up, he had no symptoms and continued to play football.

Generally, there is a history of overuse in the background of apophysitis in athletes. Overuse injury to a tissue results from repetitive submaximal loading. The process starts when repetitive activity fatigues a specific structure such as tendon or bone. With sufficient recovery, the tissue adapts to the demand and is able to undergo further loading without injury. Without adequate recovery, microtrauma develops and stimulates the body's inflammatory response, causing the release of vasoactive substances, inflammatory cells, and enzymes that damage local tissue. ${ }^{15}$ As we observed apophysitis in both the knee and ASIS on the right side, the dominant kicking side of the patient, cumulative microtrauma from repetitive activity may be one of the underlining causes of this clinical injury.

In conclusion, when apophysitis is diagnosed in an adolescent athlete, other regions exposed to high loads should also be evaluated. 


\section{What is already known on this topic}

Apophysitis describes a chronic traction injury at the tendon insertion site. It is characterised by gradual onset of pain with no clear history of injury. An apophyseal avulsion fracture is usually acute, and the displaced fragment may be bony or cartilaginous. Apophyseal injuries occur in skeletally immature patients.

\section{Authors' affiliations}

M N Doral, S T Aydog, O Tetik, O A Atay, E Turhan, H A Demirel, Department of Orthopedics and Department of Sports Medicine, Hacettepe University, Ankara, Turkey

Competing interests: none declared

Patient consent was obtained to publish figure 6.

Correspondence to: Dr Doral, Department of Orthopedics and Department of Sports Medicine, Hacettepe University Medical School, Ankara 06100, Turkey; mn-doral@bim.net.tr

Accepted 20 July 2004

\section{REFERENCES}

1 Browning $\mathrm{KH}$. Hip and pelvis injuries in runners: careful evaluation and tailored management. Phys Sportsmed 2001 ;29:23-34

2 Gross ML, Nasser S, Finerman GA. Hip and pelvis. In: Delee JC, Drez D Jr, eds. Orthopaedic sports medicine: principles and practice. Philadelphia: Saunders, 1994:1063-85.

3 Yildiz C, Aydin T, Yildiz Y, et al. Anterior inferior iliac spine apophyseal avulsion fracture. J South Orthop Assoc 2003;12:38-40.
What this study adds

Treatment of apophysitis should be undertaken more seriously than previously to prevent serious situations such as avulsion fractures. When apophysitis is diagnosed in an adolescent athlete, other regions exposed to high loads should also be evaluated.

4 Rossi F, Dragoni S. Acute avulsion fractures of the pelvis in adolescent competitive athletes: prevalence, location and sports distribution of 203 cases collected. Skeletal Radiol 2001;30:127-31.

5 Segawa H, Omori G, Koga Y. Multiple osteochondroses of bilateral knee joints. J Orthop Sci 2001;6:286-9.

6 Wall EJ. Osgood-Schlatter disease: practical treatment for a self-limiting condition. Phys Sportsmed 1998:26:29-34.

7 Tüzüner T, Özturan KE, Karaca E, et al. Avulsion fracture of the anterior superior iliac spine in a volleyball player. Acta Orthop Traumatol Turc 2003;37:340-3.

8 Fernbach SK, Wilkinson RH. Avulsion injuries of the pelvis and proximal femur. Am J Roentgenol 1981;137:581-4.

9 Valdes M, Molins J, Acebes O. Avulsion fractures of the iliac crest in a football player. Scand J Med Sci Sports 2000;10:178-80.

10 Sundar M, Carty H. Avulsion fractures of the pelvis pelvis in children a report of 32 fractures and their outcome. Skeletal Radiolo 1994:23:85-90.

11 Pointinger H, Munk P, Poeschl GP. Avulsion fracture of the anterior superior iliac spine following apophysitis. Br J Sports Med 2003;37:361-2.

12 Beck T, Messmer P, Regazzoni P. [Unilateral apophyseal fracture of the superior anterior iliac crest: a case report]. Swiss Surg 2003:9:31-4.

13 Metzmaker JN, Pappas AM. Avulsion fractures of the pelvis. Am J Sports Med 1985;13:349-58.

14 Veselko M, Smrkoli V. Avulsion of the anterior-superior iliac spine in athletes: case reports. J Trauma 1994;36:444-6.

15 DiFiori JP. Overuse injuries in children and adolescents. Phys Sportsmed 1999;27:75-80. 